\title{
Intellectualization of Educational Resources and Analysis of Students' Training
}

\author{
Igor Yeremeyev ${ }^{1}$, Alina Dychko, ${ }^{2,}$ and Sergii Gulich ${ }^{3}$
}

\author{
${ }^{I}$ Taurida National V.I. Vernadsky University, Kyiv, Ukraine \\ ${ }^{2}$ Institute of Energy Saving and Energy Management, National Technical University of Ukraine "Igor Sikorsky Kyiv \\ Polytechnic Institute", Kyiv, Ukraine \\ ${ }^{3}$ Interregional Academy of Personnel Management, Kyiv, Ukraine \\ *Corresponding author. Email: aodi@ukr.net
}

\begin{abstract}
The study focuses on the innovative approach of intellectualization of the educational methodical materials with the development of an intellectual card of the lecture, which presents its main components, combines them with each other in the order of teaching, and presents all in graphical form as a conspectus of the lecture. It is concluded that functioning of the created system "Quality - Graduate" provides qualitative teaching of all disciplines of educational programs; effective control of the level of accumulation, assimilation and acquisition of knowledge in terms of the ability to use the material; involvement of students in scientific activity; education of future graduates in terms of understanding the social significance of their profession and in terms of human values and patriotism, dedication and understanding the need for a permanent increase their knowledge and skills through individual work for the whole active life, in other words, education of students as individuals. Application of the intellectualization of educational materials and analysis of the quality of student training provides raising the requirements for specialists of different levels, helps to identify the hidden opportunities of students, maximizes the use of their ability to adapt to the modern requirements of life, and intellectualize the processes of formation of modern man as a specialist and an active member of civil society.
\end{abstract}

Keywords: educational materials, quality of students' training, intellectual card

\section{INTRODUCTION}

Universities, as higher educational institutions and scientific organizations, generate the human capital of state with an appropriate level of education and professional skills, and therefore Universities are responsible for the country development. The aims and objectives of the development of country should be closely associated with the object and purpose of higher education and science progress $[1,2]$.

The role of young scientists at the international science development and information space can hardly be overestimated. That is the one of the main priorities of the development of higher education in Ukraine, among which there is also improving the quality of education with the focus of the Bologna process [1-5].

The course of Ukraine to Europe obliges to revise all existing norms, legislative acts, etc. from the point of view of their compliance with the European standards. The last fully applies to higher education. Today it is impossible to teach with the way as in the past century: widespread computer technologies require an adequate approach to learning, knowledge control, curriculum development, substantial updating of the content of the subjects taught, the engagement of fundamentally new disciplines, if it is caused by the requirements of modern life, etc. And for this it's a need to create a functioning, effective, "transparent" system "Quality - Graduate", which ensures quality teaching of all disciplines provided by educational programs (i.e. teaching at the modern level both in terms of methods and means, and in terms of continuous updating of the material under conditions of existing development trends, requirements of life); effective control of the level of accumulation, assimilation and acquisition of knowledge in terms of the ability to use the material; involvement of students in scientific activity; education of future graduates in terms of understanding the social significance of their profession and in terms of human values and patriotism, dedication and understanding of the need for a permanent increase their knowledge and skills through individual work for the whole active life, in other words, education of students as individuals.

The quality of education depends, under conditions of its components optimization, on the quality of teaching material, and therefore on the structure of the whole course and each lecture in particular. This structure corresponds not only to the order of teaching of particular sections and subdivisions, but also to mutual relations between them, both direct and indirect.

The novelty of the research is the development of the approach in students' training with visualization of the 
elements of the lecture (course) by the intellectual card creation to simplify the structuring and teaching of the material and to focus on those units that require more specification.

\section{PROBLEMS AND METHODOLOGY}

Building such a structure can be greatly facilitated by the following proposed approach. It is about the idea of the socalled "intellectual cards" (IK), which are widely used by psychologists to facilitate the assimilation of difficult-toread materials [6]. In order to compile an intellectual map of the lecture or even the whole course (discipline), for example, as in the case of creating a network plan, it is necessary to provide the components of lectures (disciplines) (main units, the relationship between them, indirect connections, alternative options, etc.), to combine them with each other in the order of training and to present all in graphical form as a conspectus of the lecture (course). It should be noted that the creation of an intellect card is the iterative process. Generally, a rough approximation and possible connections are made first. In this case, gaps in material are often found, or there is a need to change the emphasis of the topic being developed or to add new, previously unanticipated sections, even to change the concept or paradigm. Therefore, after the first variant IK it is necessary to analyze carefully all the material relevant to this $\mathrm{IK}$, and to make adjustments to both IK and this source material in terms of supplementing (if necessary) or in carrying out (or eliminating) those or other cross-references. Particularly important is the execution of a number of iterations when developing a fundamentally new topic that uses innovative approaches, non-traditional scientific frameworks and methodology.

For example, let's consider the process of creating the IK for the course "Environmental Monitoring". It is about working out the course "Environmental Monitoring" for students of universities for the specialty "Ecology and environmental protection" [7]. A priori, it is clear that the course should consist of several main sections: ecological problems of our time, measuring monitoring of the environment, biomonitoring, model monitoring of the environment, intelligent systems of monitoring (by the way, the final chapter appears after the first iteration when it became clear that it is indispensable and logical, based on the direction of the course), and all these sections should be tightly interconnected. It is necessary to provide comprehensive information on ecology and the modern scientific and natural picture of the world, and to show the ecological system as a component of the biosphere - a complex multilevel system capable for adaptation, emphasizing the self-similarity of the components of the ecosystem. It is important to focus separately on priority controlled parameters of the environment, and the international and national activity on environmental protection.

\section{RESULTS AND DISCUSSION}

Environmental monitoring is a major source of information on the state of the environment, so the methodology of setting up a monitoring network and measures to ensure the accuracy of monitoring data, as well as the means and measures for forming the boundaries of contaminated zones and identifying the dynamics of boundaries of contamination zones, play a special role.

Specific place here has the biomonitoring, which simplifies the problem of analysis of environmental conditions through the use of bioindicators able more objectively (including synergy effects) to assess the impact of pollution on the ecosphere, including with large areas and using a minimum of means.

Finally, another component of monitoring is the model monitoring, which main task is to predict changes in the environment and migration of contamination in case of natural and man-made disasters, forecasting long-term impact of those or other infrastructure objects in the environment (for example, choice of building or type of industrial facility), the definition of the environment (estimated) in places that are not accessible for physical monitoring. Here it is important to select adequate models, evaluate their reliability, and develop a methodology for the transition from one model (empirical) to another alternative (also empirical) in case of a significant change in the external conditions of processes in the ecosphere.

\subsection{The intellectual card as a way for the quality of training increase}

In recent time, the problems of intellectualization of automated environmental monitoring systems play a significant role in the theory and practice of such systems. In order to effectively control the environment and anticipate its changes, methods and means of intellectualization are used intensively, including banks of knowledge, data and facts. They are widely used to assess data validity and environmental decision-making, methods and plausible considerations, approaches based on the theories of fuzzy sets, catastrophes, and fractals. Finally, it is about creating expert systems that are able to ensure high monitoring efficiency and adequate decision-making on environmental and sustainable development measures.

All that is demonstrated in the IK of course, which is shown in Fig. 1 and is a graphic reflection of the discipline and is, in essence, a shortened synopsis of lectures, a kind of mnemonic scheme of course, which is quite easy to adjust and update. In the same way the IK of each lecture is created individually, which facilitates training for it. In essence, it becomes a guide (or, as it is now called, a road map), which significantly simplifies the training process because it serves as a syllabus and facilitates the logical construction and presentation of the educational material. It is worth mentioning that the IK for the content module "The methods of intellectualization of monitoring processes" (Fig. 2) of the above course was developed at 
the second iteration of the IK of discipline "Environmental Monitoring", when it became clear that special attention should be paid to the problems of intellectualization of procedures and approaches to the assessment of environmental conditions in the context of uncertainty, incompleteness and inaccessibility of certain data relevant to the problems of estimation and forecasting of environmental conditions. This is where from it arises the idea to use hybrid monitoring from the point of view to ensure the reliability of data with the fluctuations in the characteristics of the system being controlled and external conditions. At the same time it is necessary to attach the question of geographic informational systems as they are closely related to problems of intellectualization to this module, and to complete the module description with the principles of building expert systems and examples of the real expert system of evaluation of the environment in case of radiation accident at the atomic power station, connected with the radiation contamination of the atmosphere and then its spread of the local and regional character.

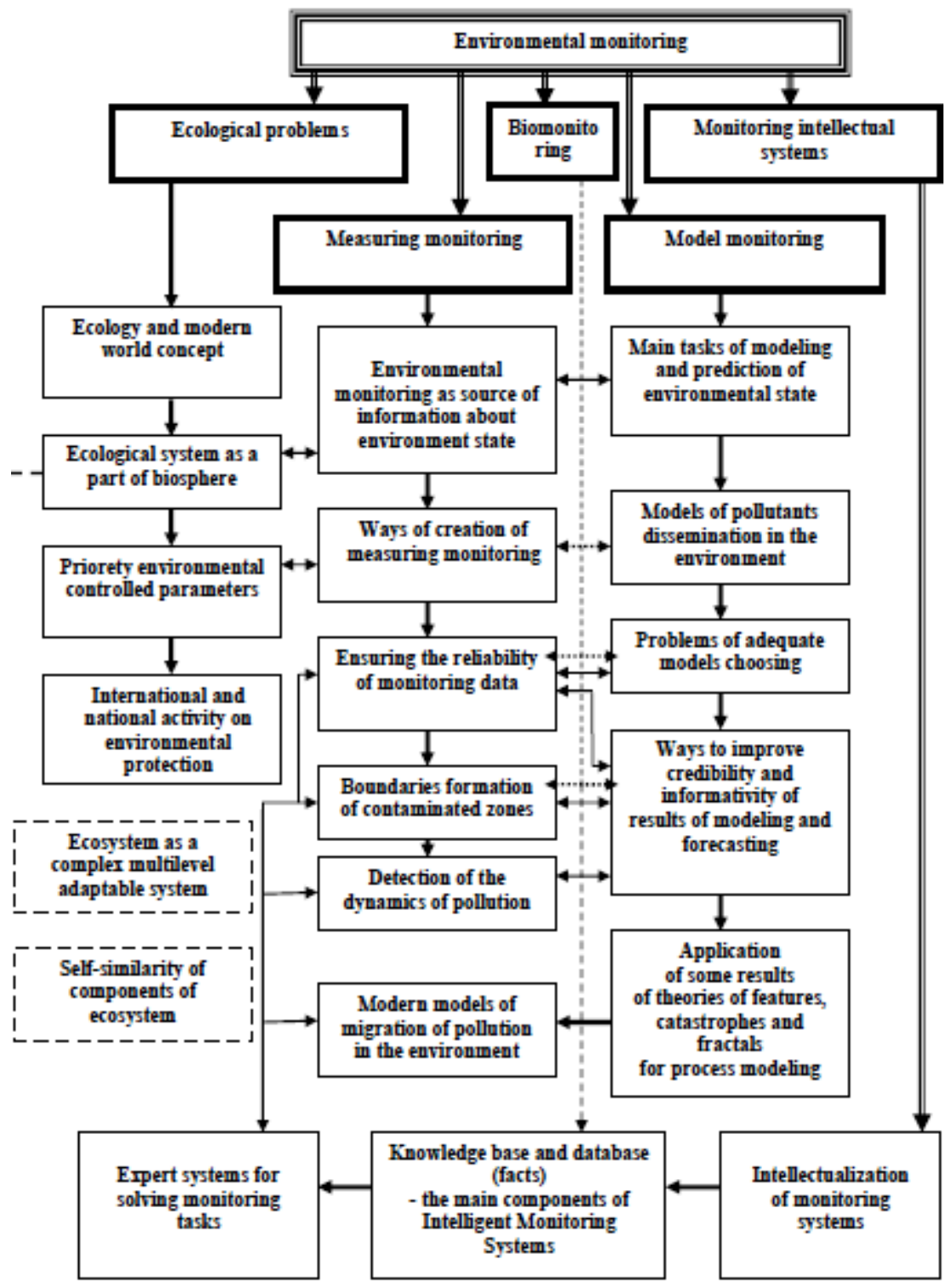

Figure 1. "Environmental Monitoring" course intellect card 


\subsection{Improvement of the quality of the educational process}

The IK use in the educational process is one of the ways of the training quality ensure. To analyse the last one effectively, it is proposed the system "Quality-Graduate", shown in Fig. 2. It consists of an entrance block, which includes pre-university training and selecting of entrants for IQ indicators, as well as the results of students' competitions; the main unit (educational process), attached to the sub-units of module control of knowledge, the organization of research work of students, stimulation of the public activity of students, as well as sub-units of updating of disciplines, input of new specialties and the redistribution of the proportion of individual disciplines.

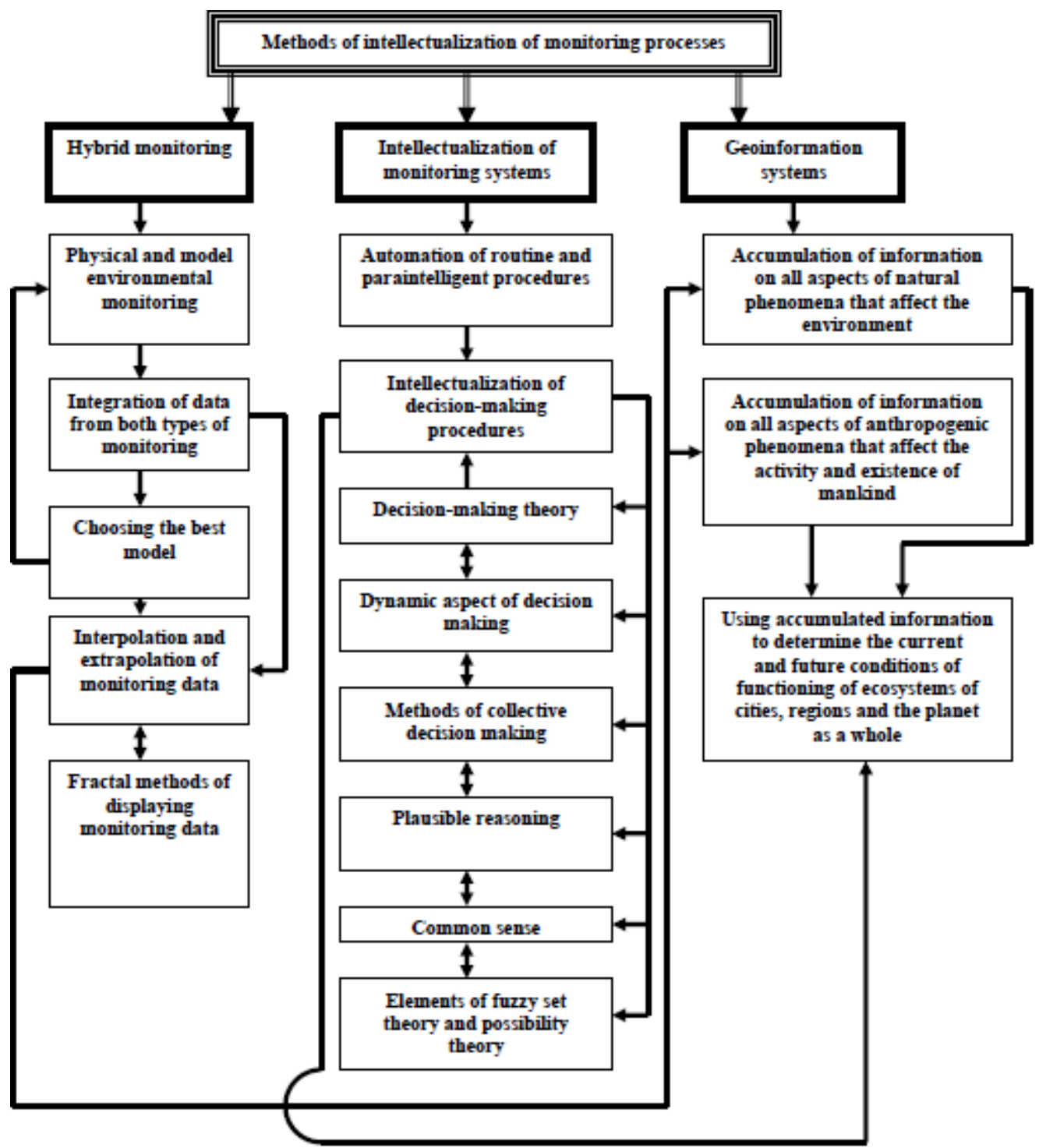

Figure 2. Module content of the intellect card "Methods of intellectualization of monitoring processes"

The results of module control, scientific and social activities of students are entered into the files of each student. Such information is rated and the permanent procedures (implemented for the whole period of study after each module control) allow to evaluate each student has success in research or training and therefore can be qualified as "master", or he should be guided to employment in industry and therefore can be qualified as "bachelor" or, finally, he has to change profession (go to another department where his skills can be more effectively used), or should be excluded from the university and should enter another school. Exit information (according to the quality assessments of graduates from the place of employment) is considered as sub-blocks "Updating disciplines", "Input of new specialties", and "Redistributing the specific proportion of the disciplines" (when stakeholders of young specialists offer this measure) and the block of adjustment of the criteria for selection of applicants. 
For the successful realization of the system proposed, it should be implemented the following steps towards the improvement of the quality of the educational process.

Teaching:

- To provide the possibility to make adjustments in the work plans that reflect the current level of understanding of the problems facing the state, and to take into account the requirements associated with the urgent need to reform all components of the educational process.

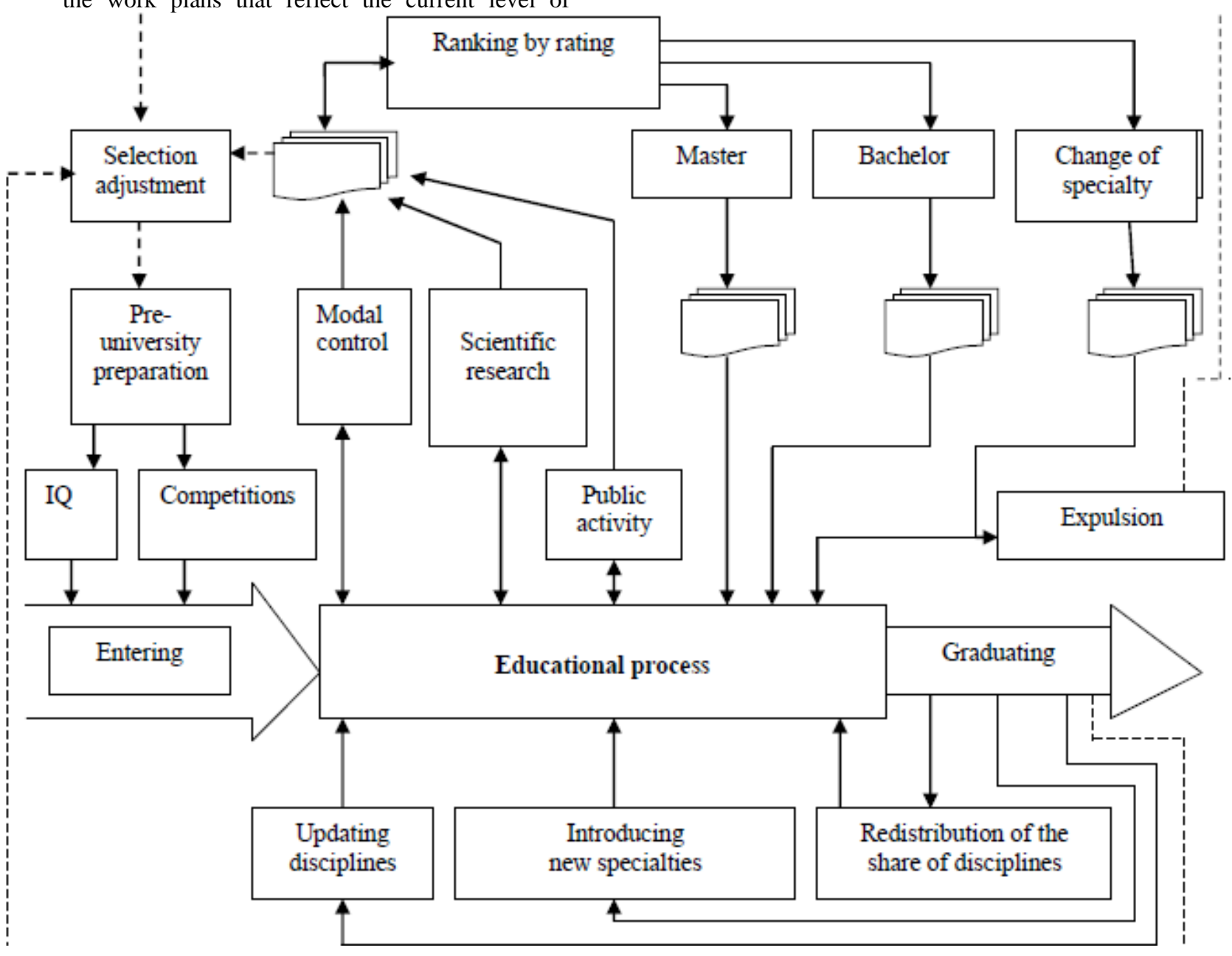

Figure 3. Block diagram of "Quality-Graduate" system

- To complete urgent work on the creation of tutorials on electronic media for the subjects taught.

- To orient students to develop non-traditional thinking and plausible reasoning.

- To strengthen significantly control of the quality of teaching.

- To organize regular professional training for teachers.

Control of knowledge:

- Particular attention should be paid to improving module control.

- To introduce a module-rating system for the evaluation of practical and seminar classes.
- To implement a feedback module of test results with the reform of the form and content of the educational process.

Scientific work:

- To integrate the modern achievements of science and technology into the subject of course and diploma works of students.

- To involve students in the scientific work of departments.

- To promote cooperation of educational and scientific institutions for solving actual problems.

Educational Activities:

- To pay attention to the necessity of creating an atmosphere of mutual respect in relations between students and teachers, based on such principles as 
accuracy and punctuality, politeness, tolerance, moderation, mutual obligations, honesty.

- To understand that communication at the informal level does not only help to find a common language, to establish contacts with students, but also to gain confidence and authority, which does not only facilitates educational and research work, but also stimulates public activity in universities.

The organization and effective use of the system offered usually require not only some costs but also the essential adjustment of the "familiar" but outdated approaches to the problem of training both students and teachers. But there is no alternative to this process: the "Quality-Graduate" system (proposed one or some other that meets the modern requirements to the higher school) is functioning or our country goes beyond the modern educational space and be left alone with its problems.

\section{CONCLUSIONS}

The proposed approach of the graphical presentation of elements of lecture (course) helps to simplify significantly structuring and teaching of material, facilitates the perception of topic, simplifies note-taking, helps to focus on those units that require more specification. At the same time, the approach to the analysis of the quality of student pre-study provides raising the requirements for specialists of different levels, helps to identify the hidden opportunities of students, maximizes the use of their ability to adapt to the modern requirements of life and, finally, the intellectualization of the processes of formation of modern man as a specialist and an active member of a civil society

\section{REFERENCES}

[1] M. Z. Zgurovsky, The Bologna process: main principles and ways of structural reform of higher education in Ukraine, Kyiv, NTUU “KPI”, 2006, p. 544.

[2] M. Z. Zgurovsky, Higher education reform is a necessary factor in social change, Kyiv, Kyivskiy Polytechnic, 2012, Retrieved from http://kpi.ua/1203-1. Accessed 10 January 2020.

[3] O. Dzhura, The Bologna Process as a manifestation of educational modernization, Higher education of Ukraine, 2008, 4, pp. 58-63.

[4] G. Kalinicheva, The European Integration Progress of Higher Education in Ukraine: New Opportunities or New Problems? (Viche, Kyiv, 2009), http://veche.kiev.ua/journal/1594/ Accessed 10 January 2020.

[5] A. Dychko, L. Yevtieieva, Ukrainian higher education modernisation with the US and EU focus [Digests 2nd International Conference on the USA in the modern world: politics, economics, law, society, Ivan Franko National University of Lviv, Lviv, pp. 636$638,2015$.

[6] T. Buzan, Mind Map Handbook, Thorsons, 2013.

[7] I. S. Eremeev, A. O. Dychko, Environmental monitoring, Kyiv, Center for Educational Literature, 2016, p. 500. 